\title{
Seafood Processing Chitin Waste for Electricity Generation in a Microbial Fuel Cell Using Halotolerant Catalyst Oceanisphaera arctica YHY1
}

\author{
Ranjit Gurav ${ }^{1}{ }^{1}$, Shashi Kant Bhatia ${ }^{1}{ }^{\circledR}$, Tae-Rim Choi ${ }^{1}$, Hyun-Joong Kim ${ }^{1}$, Hong-Ju Lee ${ }^{1}$, Jang-Yeon Cho ${ }^{1}$, \\ Sion Ham ${ }^{1}$, Min-Ju Suh ${ }^{1}$, Sang-Hyun Kim ${ }^{1}$, Sun-Ki Kim ${ }^{2}$, Dong-Won Yoo $^{3}$ and Yung-Hun Yang ${ }^{1, *}$
}

\section{check for} updates

Citation: Gurav, R.; Bhatia, S.K.; Choi, T.-R.; Kim, H.-J.; Lee, H.-J.; Cho, J.-Y.; Ham, S.; Suh, M.-J.; Kim, S.-H.; Kim, S.-K.; et al. Seafood Processing Chitin Waste for

Electricity Generation in a Microbial Fuel Cell Using Halotolerant Catalyst Oceanisphaera arctica YHY1.

Sustainability 2021, 13, 8508 . https://doi.org/10.3390/su13158508

Academic Editor: Dino Musmarra

Received: 15 June 2021

Accepted: 26 July 2021

Published: 29 July 2021

Publisher's Note: MDPI stays neutral with regard to jurisdictional claims in published maps and institutional affiliations.

Copyright: (c) 2021 by the authors. Licensee MDPI, Basel, Switzerland. This article is an open access article distributed under the terms and conditions of the Creative Commons Attribution (CC BY) license (https:/ / creativecommons.org/licenses/by/ $4.0 /)$.
1 Department of Biological Engineering, College of Engineering, Konkuk University, Seoul 05029, Korea; rnjtgurav@gmail.com (R.G.); shashibiotechhpu@gmail.com (S.K.B.); srim1004@gmail.com (T.-R.C.); sopero2@naver.com (H.-J.K.); oneul1210@naver.com (H.-J.L.); whwkddus1123@gmail.com (J.-Y.C.); sion1403@naver.com (S.H.); semn0702@konkuk.ac.kr (M.-J.S.); tkdgus5257@nate.com (S.-H.K.)

2 Department of Food Science and Technology, Chung-Ang University, Anseong 17546, Korea; skkim18@cau.ac.kr

3 School of Chemical and Biological Engineering, Seoul National University, Seoul 08826, Korea; dwyoo@snu.ac.kr

* Correspondence: seokor@konkuk.ac.kr

\begin{abstract}
In this study, a newly isolated halotolerant strain Oceanisphaera arctica YHY1, capable of hydrolyzing seafood processing waste chitin biomass, is reported. Microbial fuel cells fed with $1 \%$ chitin and $40 \mathrm{~g} \mathrm{~L}^{-1}$ as the optimum salt concentration demonstrated stable electricity generation until $216 \mathrm{~h}\left(0.228 \mathrm{~mA} / \mathrm{cm}^{2}\right)$. N-acetyl-D-glucosamine (GlcNAc) was the main by-product in the chitin degradation, reaching a maximum concentration of $192.01 \mathrm{mg} \mathrm{g}^{-1}$ chitin at $120 \mathrm{~h}$, whereas lactate, acetate, propionate, and butyrate were the major metabolites detected in the chitin degradation. $O$. arctica YHY1 utilized the produced GlcNAc, lactate, acetate, and propionate as the electron donors to generate the electric current. Cyclic voltammetry $(\mathrm{CV})$ investigation revealed the participation of outer membrane-bound cytochromes, with extracellular redox mediators partly involved in the electron transfer mechanism. Furthermore, the changes in structural and functional groups in chitin after degradation were analyzed using FTIR and XRD. Therefore, the ability of O. arctica YHY1 to utilize waste chitin biomass under high salinities can be explored to treat seafood processing brine or high salt wastewater containing chitin with concurrent electricity generation.
\end{abstract}

Keywords: chitin; electricity generation; halotolerant; microbial fuel cell; seafood processing

\section{Introduction}

The seafood processing industry produces a substantial amount of wastewater, mainly containing soluble, colloidal, and particulate matter. Among crustaceans, the total production of shrimp reached 5.03 million tons in 2020 and is estimated to increase to 7.28 million tons by 2025, with a compound annual growth rate of $6.1 \%$ from 2020 to 2025 and 67.6 billion USD turnover [1]. Asia alone contributes more than $80 \%$ of the global shrimp production, where Thailand is the major exporter of cultivated shrimp to the USA, Canada, Europe, South Korea, and Japan [2]. Depending on the market requirements, shrimp is exported or stored in frozen conditions with or without an outer shell. For shrimp processing, a huge amount of water is required, generating around $1000 \mathrm{~L}$ of highly polluted wastewater per ton of shrimp [1,3]. Shrimp processing produces $50-60 \%$ of solid waste comprising the head, viscera, and shell, which are discarded as the by-products generated in processing. The biochemical composition of shrimp waste mainly contains $15-46 \%$ chitin, 30-60\% minerals, $10-40 \%$ protein, and $10-40 \%$ lipids [1,4]. Similarly, the salinity of the seafood processing wastewater is another important factor that mainly depends on the products or species being processed. The precooking or 
brine treatment for the canning of shrimp generates wastewater, with the $\mathrm{NaCl}$ concentration ranging between $20-30 \mathrm{~g} \mathrm{~L}^{-1}$ [5].

Chitin is the second most abundant natural biopolymer, consisting of monomeric units of GlcNAc linked with $(1,4)$ - $\beta$-linkages [6]. The microbial chitinase (EC 3.2.2.14) is a glycoside hydrolytic enzyme capable of hydrolyzing chitin into GlcNAc or oligomers and utilizing it as a source of carbon for growth and development [7]. Chitin waste has been partly used as animal feed, as a component of aquaculture feed formulation, and for the recovery of bioactive molecules. However, a large amount of chitin biomass is being wasted, which increases environmental pollution [1]. However, particulate substrates like chitin can be inexpensive, easily available, and renewable feedstock in microbial fuel cells (MFCs) for electricity production [8]. The MFC is a bio-electrochemical system that can break and utilize chitin more effectively compared to normal fermentation conditions, owing to the anode working as an electron acceptor $[7,8]$. Several natural and synthetic substrates, including acetate, glucose, lactate, amino acids, butyrate, formate, fumarate, alcohols, or complex carbohydrates like cellulose, sucrose, molasses, starch, or industrial and domestic wastewater, were widely researched as fuels for MFCs [8,9]. However, high production costs and easy depletion have constrained the use of synthetic substrates in MFCs. Nevertheless, chitin waste can be an alternative synthetic substrate source for sustainable energy production by using bacteria as a catalyst to oxidize organic substrates directly into electrical energy. Previously, chitin has been utilized as a substrate by Bacillus circulans, Arenibacter palladensis, Shewanella oneidensis, Aeromonas hydrophila, or as sediment wastewater-based systems for electricity production $[7,10]$.

Therefore, in the present study, a newly isolated halotolerant marine bacterium $O$. arctica YHY1 capable of hydrolyzing chitin waste was studied as a biocatalyst for electricity generation in MFCs. Furthermore, the electrochemical parameters, the structural changes in chitin before and after degradation, and the by-products or metabolites of degradation were analyzed.

\section{Materials and Methods}

\subsection{Chitin Preparation, Isolation, and Identification of Chitin Degrading Microbes}

The shrimp shell chitin was obtained from the local seafood processing unit near Seoul, South Korea. The obtained chitin biomass was washed, dried, and pre-treated according to the method reported earlier by Gurav et al. [10]. The resulting colloidal chitin was dried and stored in a refrigerator for further applications. Isolation of chitinolytic microbes was performed using marine soil collected from a beach near Geoje $\left(34^{\circ} 51^{\prime} 16.5^{\prime \prime}\right.$ $\mathrm{N} 128^{\circ} 43^{\prime} 43.9^{\prime \prime} \mathrm{E}$ ), Eastern Sea of South Korea. In brief, one gram of soil was serially diluted and smeared on the chitin agar plates containing $(\mathrm{g} \mathrm{L}-1) 0.7-\mathrm{KH}_{2} \mathrm{PO}_{4}, 0.3-\mathrm{K}_{2} \mathrm{HPO}_{4}$, $5.0-\mathrm{NaCl}, 0.5-\mathrm{MgSO}_{4}, 0.0001-\mathrm{ZnSO}_{4}, 0.0001-\mathrm{MnSO}_{4}, 10$-chitin, and 25-agar [6,10]. Seven morphologically different strains showing clear zones were isolated and cultured as a monoculture on chitin-agar plates. These seven strains were initially tested for electric current production in MFCs supplemented with $1 \%$ chitin. Based on its higher chitin degradation and electricity generation ability, strain YHY1 was selected for identification by using $16 \mathrm{~S}$ rRNA gene sequencing.

\subsection{MFC Setup and Electrochemical Analysis}

As shown in Figure 1, a dual-chamber MFC consisting of cathodic and anodic chambers separated by a proton exchange membrane (Nafion 212, Omniscience, Yongin, Korea) was assembled. The anodic chamber was equipped with $2.25 \mathrm{~cm}^{2}$ carbon felt and a silver reference electrode $(\mathrm{Ag} / \mathrm{AgCl})$, whereas the cathodic chamber contained $4 \mathrm{~cm}^{2}$ platinumcoated carbon felt. Degassed growth media containing $\left(\mathrm{g} \mathrm{L}^{-1}\right) 0.7-\mathrm{KH}_{2} \mathrm{PO}_{4}, 0.3-\mathrm{K}_{2} \mathrm{HPO}_{4}$, $40-\mathrm{NaCl}, 0.5-\mathrm{MgSO}_{4}, 0.0001-\mathrm{ZnSO}_{4}, 0.0001-\mathrm{MnSO}_{4}$, and 10 -chitin was inoculated with $1 \%$ $v / v$ inoculum with an optical density of $0.9 \pm 0.05$ at the anodic chamber, whereas $50 \mathrm{~mL}$ phosphate buffer ( $\mathrm{pH} 7.0 ; 50 \mathrm{mM}$ ) containing $50 \mathrm{mM}$ ferricyanide was filled at the cathode chamber. The anode and cathode were connected through a potentiostat (WizECM-8100 
premium, Wizmac, Daejeon, Korea) and operated as a closed-circuit using an external resistance of $1000 \Omega[7,8,11,12]$. The current output density $\left(\mathrm{mA} / \mathrm{cm}^{2}\right)$ of the system was recorded and plotted versus time (h). To investigate the electrocatalytic behavior and interaction between the redox mediator, electrode, and anodic biofilm, the CV was performed using a three-electrode system including working, counter, and reference electrodes with a $10 \mathrm{mV} / \mathrm{S}$ scan rate and $\mathrm{a}+1 \mathrm{~V}$ to $-1 \mathrm{~V}$ potential range.

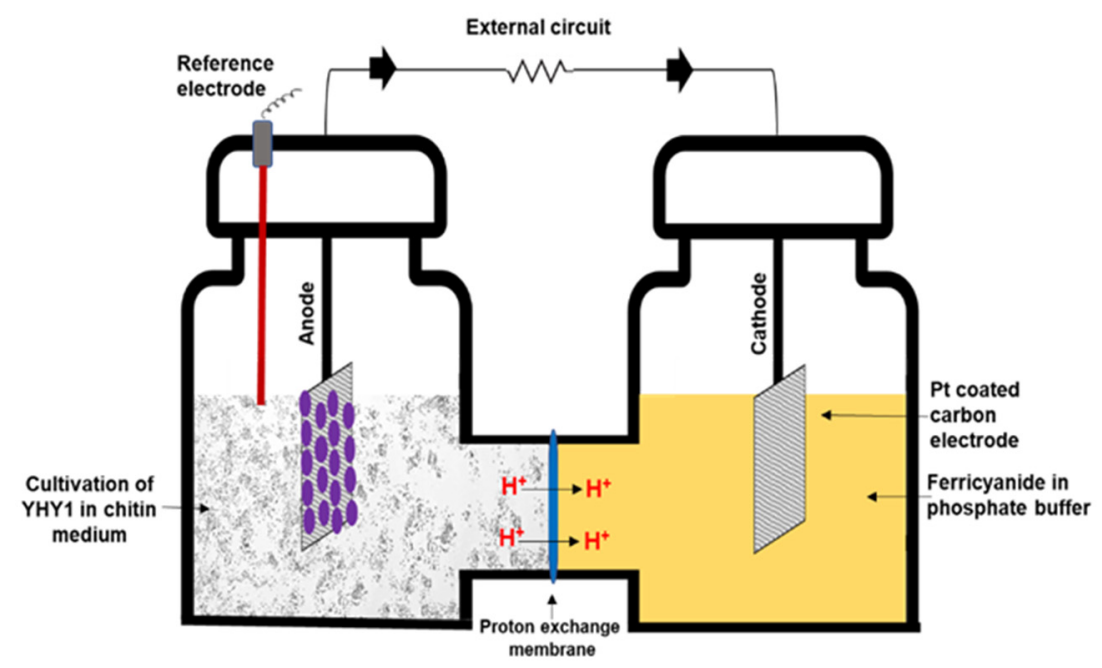

Figure 1. Setup of the dual-chamber MFC.

\subsection{Analysis of Degradation Products}

HPLC (Young Lin, YL-9100, Seoul, Korea) investigation was performed to quantify free GlcNAc in the degradation media using a C18 column (ZORBAX, SBC18) and acetonitrile: water $(20: 80)$ as the mobile phase $[7,10]$. Further, the metabolic profiling of the chitin degradation media was performed using HPLC (Bio-Rad, Hercules, CA, USA) equipped with Bio-Rad Aminex HPX-87H column and $5 \mathrm{mM} \mathrm{H}_{2} \mathrm{SO}_{4}$ as the solvent phase [13].

\subsection{SEM, XRD and FTIR Analysis}

SEM (Hitachi TM4000Plus, Tokyo, Japan) was performed to investigate the anodic biofilm [9]. The FTIR (Nicolet 6700, Thermo Fisher Scientific, Waltham, MA, USA) was executed to verify the structural changes in the chitin before and after degradation in MFCs [7,10], whereas XRD (D8 ADVANCE-DAVINCI, Bruker, Bremen, Germany) was examined to determine changes in the crystallinity of chitin. The crystalline index (CrI, \%) was calculated from the XRD data using the following equations [10,14].

$$
\mathrm{CrI}_{020}=\left[\left(\mathrm{I}_{020}-\mathrm{Iam}\right) / \mathrm{I}_{020} \times 100\right]
$$

where $\mathrm{I}_{020}$ and $\mathrm{I}_{\mathrm{am}}$ is the maximum intensity at $2 \theta \cong 9^{\circ}$ and the intensity of amorphous diffraction at $2 \theta \cong 16^{\circ}$, respectively.

$$
\mathrm{CrI}_{110}=\left[\left(\mathrm{I}_{110}-\mathrm{I}_{\mathrm{am}}\right) / \mathrm{I}_{110} \times 100\right]
$$

where $\mathrm{I}_{110}$ is the maximum intensity at $2 \theta \cong 20^{\circ}$.

\section{Results}

\subsection{Identification, and Salt-Tolerance in the Chitinolytic Bacterium}

Seven chitin degrading strains were newly isolated from the marine soil, where strain YHY1 showed maximum chitin hydrolysis activity with a zone diameter of $20 \mathrm{~mm}$ on chitin agar plates. The $16 \mathrm{~S}$ rRNA sequencing data of strain YHY1 revealed $96 \%$ similarity with Oceanisphaera arctica strain V1-41; therefore, strain YHY1 was designated as Oceanisphaera arctica YHY1. The phylogenetic position of strain YHY1 and other allied strains is depicted 
in Figure 2a. The obtained gene sequence (989 bp) was submitted to Genbank under accession no. MH590704. Furthermore, the salt tolerance in strain YHY1 showed better growth on increasing the salt concentration from $5 \mathrm{~g} \mathrm{~L}^{-1}$ to $40 \mathrm{~g} \mathrm{~L}^{-1}$, suggesting the necessity of salt for growth (Figure $2 \mathrm{~b}$ ). This strain was able to tolerate up to $80 \mathrm{~g} \mathrm{~L}^{-1}$ of salt concentration; however, concentrations above $80 \mathrm{~g} \mathrm{~L}^{-1}$ significantly inhibited the growth of the bacterium.

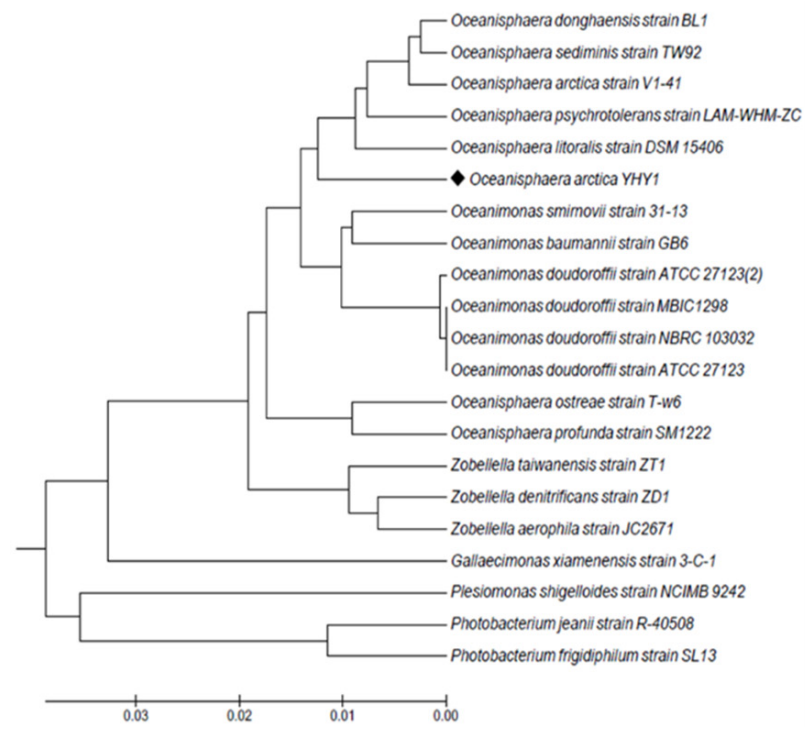

(a)

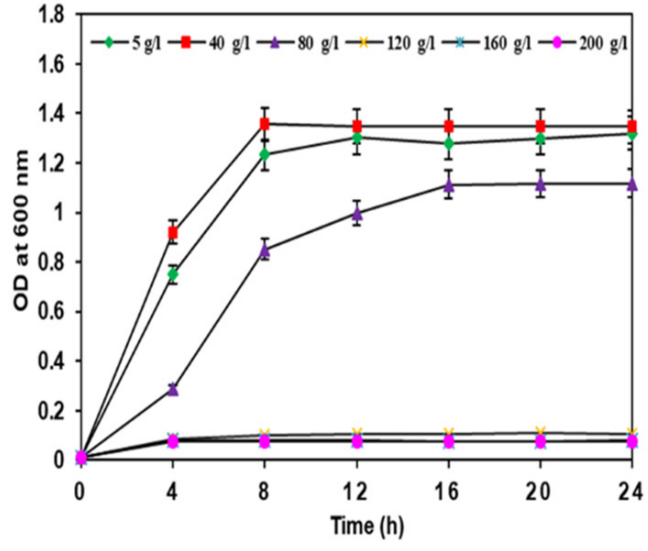

(b)

Figure 2. (a) Phylogenetic position of O. arctica YHY1; (b) Salt tolerance in strain YHY1.

\subsection{Electrochemical Assessment of MFCs Fueled with Chitin Waste}

Depleting non-renewable energy resources has enabled researchers to discover new sustainable energy assets. In MFCs, microbes act as the biocatalysts that transform the chemical energy of organic residues into electricity $[10,15]$. In this study, halotolerant O. arctica YHY1 was investigated for electricity production using seafood processing waste chitin as the carbon source. As shown in Figure 3a, the performance of MFCs fueled with $1 \%$ chitin biomass was studied, with a fixed external resistance of $1000 \Omega$ and $40 \mathrm{~g} \mathrm{~L}^{-1} \mathrm{NaCl}$. After inoculating the MFCs with O. arctica YHY1, a rapid increase in electricity generation was observed in the MFCs, with a maximum current output density reaching $0.302 \mathrm{~mA} / \mathrm{cm}^{2}$ at $12 \mathrm{~h}$. Higher current production in the initial period could be related to the free GlcNAc ( $12.311 \mathrm{mg} \mathrm{g}^{-1}$ chitin) that was produced during the pre-treatment of the chitin. A similar mechanism has been reported earlier in Aeromonas hydrophila, Bacillus circulans, and Shewanella oneidensis MFCs using chitin as the carbon source $[7,11,12]$. However, the current output density slightly dropped to $0.210 \mathrm{~mA} / \mathrm{cm}^{2}$ after $20 \mathrm{~h}$; this might be due to depletion in free GlcNAc. Thereafter, the electricity generation was enhanced and remained almost constant until $216 \mathrm{~h}\left(0.228 \mathrm{~mA} / \mathrm{cm}^{2}\right)$. Previously, chitin or pure GlcNAc has been reported as an electron donor in electricity production in MFCs using various microbial catalysts. For instance, Aeromonas hydrophila and Shewanella oneidensis fed with $0.2 \%$ chitin produced $8.77 \mu \mathrm{A} / \mathrm{cm}^{2}$ and $4.24 \mu \mathrm{A} / \mathrm{cm}^{2}$, whereas using pure GlcNAc produced $6.65 \mu \mathrm{A} / \mathrm{cm}^{2}$ and $6.17 \mu \mathrm{A} / \mathrm{cm}^{2}$ of current output density, respectively [11,12]. Similarly, Arenibacter palladensis and Bacillus circulans produced $15.15 \mu \mathrm{A} / \mathrm{cm}^{2}$ and $26.508 \mu \mathrm{A} / \mathrm{cm}^{2}$ current output density, respectively, in MFCs fed with $1 \%$ chitin $[7,10]$. However, in the present study, a stable and higher current output density of $0.228 \mathrm{~mA} / \mathrm{cm}^{2}(216 \mathrm{~h})$ was observed in O. arctica YHY1 using $1 \%$ chitin and $40 \mathrm{~g} \mathrm{~L}^{-1}$ salt concentration. Salinity played an important role in the MFCs in the present study. The MFCs were supplied with $40 \mathrm{~g} \mathrm{~L}^{-1} \mathrm{NaCl}$ as the optimized salt concentration for $O$. arctica YHY1. The salinity of the media has a positive impact on electricity generation 
as it decreases the internal resistance of the system and increases media conductivity. Furthermore, higher salinity can also prevent the acidification of the media due to the fast transfer of $\mathrm{H}^{+}$ions from the anode to the cathode $[9,16]$.

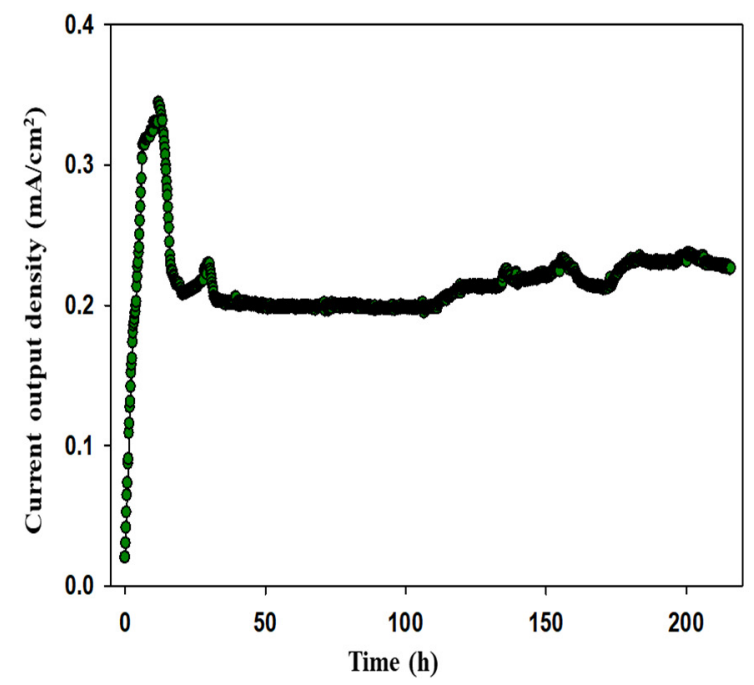

(a)

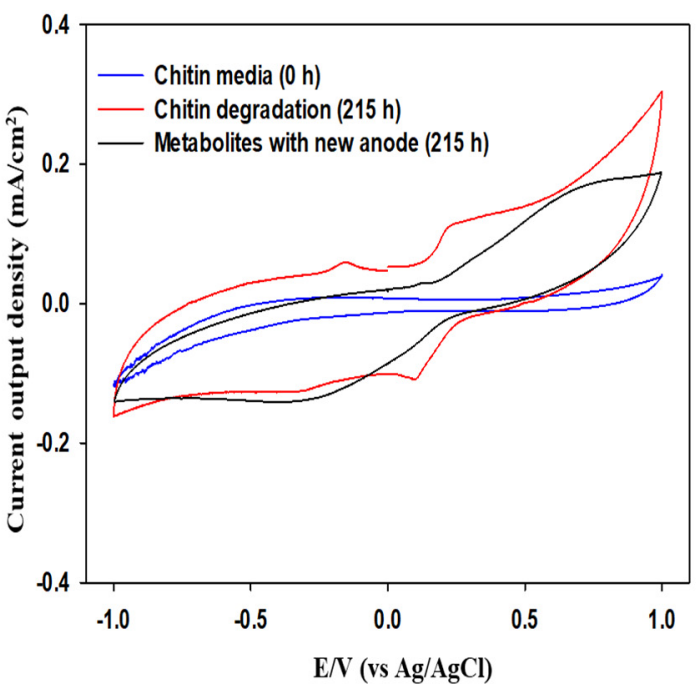

(b)

Figure 3. (a) Performance of strain YHY1 in MFCs fed with $1 \%$ chitin, $40 \mathrm{~g} \mathrm{~L}^{-1} \mathrm{NaCl}$, and external load of $1000 \Omega$; (b) CV of the MFCs fed with chitin. Plots represent the CV of media without inoculum $(0 \mathrm{~h}), \mathrm{CV}$ of media at $216 \mathrm{~h}$ of growth, $\mathrm{CV}$ of cell-free metabolites with a new anode.

CV studies were executed to reveal the electrochemical behavior of O. arctica YHY1 in MFCs fed with chitin. As depicted in Figure 3b, the initial CV profile of chitin media $(0 \mathrm{~h})$ without bacterial inoculation did not show any oxidation-reduction peaks, indicating a lack of redox mediators in the medium. However, the CV of MFCs at $216 \mathrm{~h}$ after inoculation showed distinct oxidation peaks at $-0.15 \mathrm{~V}$ (vs. $\mathrm{Ag} / \mathrm{AgCl}$ ), and $+0.20 \mathrm{~V}$ (vs. $\mathrm{Ag} / \mathrm{AgCl}$ ), reduction peaks at $+0.10 \mathrm{~V}$ (vs. $\mathrm{Ag} / \mathrm{AgCl}$ ), and a broad peak at $-0.40 \mathrm{~V}$ (vs. $\mathrm{Ag} / \mathrm{AgCl}$ ) (Figure 3b). During the forward scan, a higher current output density of $0.302 \mathrm{~mA} / \mathrm{cm}^{2}$ was observed, indicating higher oxidation reactions were recorded, as compared to the reductions reported earlier [7,17]. The CV of the cell-free degradation metabolites after the filtration and insertion of a new anode showed a broad oxidation-reduction peak at,$+-0.40 \mathrm{~V}$ (vs. $\mathrm{Ag} / \mathrm{AgCl}$ ), suggesting production of a low quantity of soluble redox mediators in the chitin degraded medium. The observed formal potential of $0.200 \mathrm{~V}$ (vs. $\mathrm{Ag} / \mathrm{AgCl}$ ) can be related to the outer membrane-bound cytochrome, which can transfer the electrons directly to the electrode without any external redox mediators, as reported earlier in Shewanella [18]. Further, a formal potential of $-0.15 \mathrm{~V}$ (vs. Ag/AgCl) was detected similar to Geobacter sulfurreducens, which generally use omcB to transfer electrons through the electrode/biofilm interface [19-22]. Similarly, the low amount of flavins might have been produced by $\mathrm{O}$. arctica YHY1 with the formal potential of $0.40 \mathrm{~V}$ (vs. Ag/ $\mathrm{AgCl}$ ), as reported earlier [23]. Therefore, from the $\mathrm{CV}$ data, it could be predicted that $O$. arctica YHY1 mainly utilizes a direct electron transfer pathway to transfer electrons directly to the electrode surface using membrane-bound cytochromes. Furthermore, this bacterium also partly employs the indirect electron transfer pathway using extracellular redox mediators to shuttle electrons to the electrode. However, more detailed study at a molecular level is needed to find the exact mechanism used by O. arctica YHY1 to transfer electrons from bacteria to the electrode surface.

\subsection{Chitin Degradation By-Products and Other Metabolites}

Chitinolytic microbes can hydrolyze chitin biopolymer into monomeric or dimeric GlcNAc units and utilize them as the source of energy. In the present study, monomeric 
GlcNAc was the main by-product of chitin hydrolysis by O. arctica YHY1 in MFCs. The concentration of GlcNAc at $24 \mathrm{~h}$ was $58.21 \mathrm{mg} \mathrm{g}^{-1}$ chitin, which was significantly increased to $192.01 \mathrm{mg} \mathrm{g}^{-1}$ at $120 \mathrm{~h}$. However, after $120 \mathrm{~h}$, the concentration of GlcNAc was gradually decreased to $76.22 \mathrm{mg} \mathrm{g}^{-1}$ at $216 \mathrm{~h}$. From these results, it could be concluded that until $120 \mathrm{~h}$, chitin was efficiently degraded, with simultaneous utilization of GlcNAc. Thereafter, depletion in the chitin concentration in media might have terminated the chitinase-producing machinery or inhibited the enzyme activity due to the generation of toxic intermediate metabolites $[7,24]$. However, O. arctica YHY1 continued to utilize the produced GlcNAc with the concurrent electricity generation until $216 \mathrm{~h}$. During hydrolysis of the chitin, several metabolites were detected in the MFCs, with lactate, acetate, propionate, and butyrate as the prominent metabolites. The highest concentration of acetate, $5.901 \mathrm{mM}(144 \mathrm{~h})$, was detected, followed by butyrate, $3.572 \mathrm{mM}(96 \mathrm{~h})$, lactate, $0.932 \mathrm{mM}$ $(96 \mathrm{~h})$, and propionate, $0.157(120 \mathrm{~h})$ (Figure $4 \mathrm{a})$. Acetate, lactate, and propionate were most preferred by O. arctica YHY1, with $1.593 \mathrm{mM}, 0.110 \mathrm{mM}$, and $0.099 \mathrm{mM}$ concentrations, respectively, remaining unutilized at $216 \mathrm{~h}$. However, butyrate was strain YHY1's less favored electron donor $(2.533 \mathrm{mM} ; 216 \mathrm{~h})$. Although the GlcNAc content was depleted after $120 \mathrm{~h}$ of growth, the current output density remained stable as the bacterium also utilized produced metabolites like lactate and acetate for growth, which correlates with the previous report on chitin as the carbon source in MFCs [7]. In Shewanella, lactate is first produced, followed by pyruvate, and acetate, and thus the carbon source preference can be in the following order: lactate $\rightarrow$ pyruvat $\rightarrow$ acetate [25]. The lactate concentration was higher at $96 \mathrm{~h}$ whereas acetate was higher at $144 \mathrm{~h}$, although both concentrations decreased after reaching the maximum concentration, suggesting lactate can be oxidized to acetate [26]. During chitin hydrolysis, the production of metabolites like lactate, acetate, butyrate, succinate, format, and propionate was reported earlier in Shewanella oneidensis, Bacillus circulans, Arenibacter palladensis, and Aeromonas hydrophila [7,10-12].

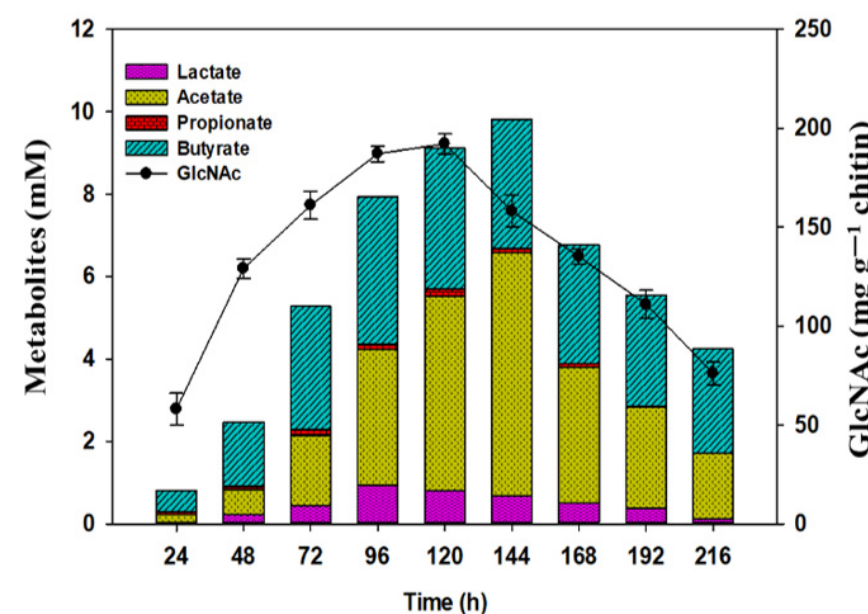

(a)

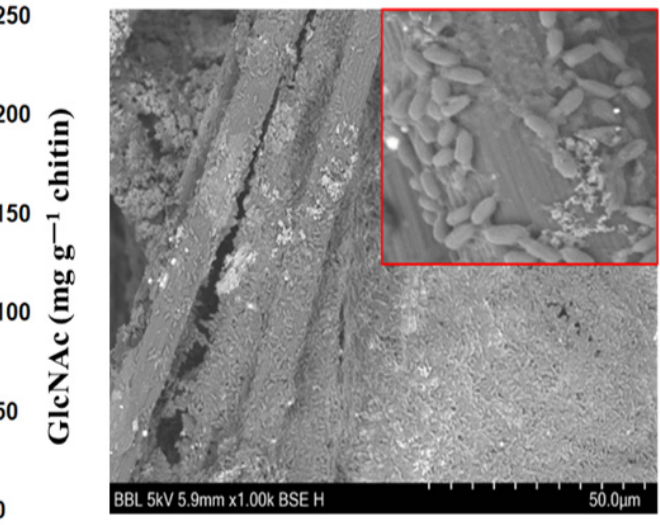

(b)

Figure 4. (a) Production and utilization of GlcNAc and other metabolites in MFC; (b) SEM examination of anodic biofilm.

SEM investigation of the anodic biofilm of $O$. arctica YHY1 revealed a thick biofilm formation on the anode surface (Figure $4 \mathrm{~b}$ ). This result could also be correlated with the CV data, suggesting that membrane-bound cytochromes were principally involved in direct electron transfer to the anode.

\subsection{Investigating Structural Changes in Chitin Polymer in MFCs}

As shown in Figure 5a, chitin biopolymer has a typical band pattern for amide bonds at 1660 and $1630 \mathrm{~cm}^{-1}$ (amide I), $1558 \mathrm{~cm}^{-1}$ (amide II), $1318 \mathrm{~cm}^{-1}$ (amide III), and $693 \mathrm{~cm}^{-1}$ (amide V) [7,27]. Similarly, an IR peak at $1028 \mathrm{~cm}^{-1}$ assigned to stretching vibration for $-\mathrm{C}-\mathrm{O}-\mathrm{C}$ of the glucosamine ring, and a peak at $890 \mathrm{~cm}^{-1}$ related to ring stretching for 
$\beta-1,4$ glycosidic bonds were detected in the chitin [28]. Nevertheless, on the degradation of chitin in MFCs, the band intensity at $1660 \mathrm{~cm}^{-1}$ (amide I), $1378 \mathrm{~cm}^{-1}$ (amide III), and $1080 \mathrm{~cm}^{-1}$ (C-O stretching) substantially decreased, suggesting breaking of the $\mathrm{C}-\mathrm{O}$ and $\mathrm{C}-\mathrm{H}$ bonds $[7,10]$. Likewise, the XRD analysis revealed alterations in the crystallinity of the chitin before and after degradation (Figure $5 b$ ). The diffraction pattern of chitin before degradation showed distinct peaks at lattice (020), (110), (120), (101), and (130) [7]. Strong reflections were detected at $2 \theta 9.45^{\circ}, 19.05^{\circ}$, and $31.46^{\circ}$, whereas other peaks were detected at $12.93^{\circ}, 20.09^{\circ}, 23.60^{\circ}$, and $26.51^{\circ}$. The crystalline index (CrI) of the chitin before and after degradation was calculated considering reflections at (020) and (110). Initial $\mathrm{CrI}(020)$ and CrI(110) of the chitin were $74.41 \%$ and $83.60 \%$, respectively, which significantly decreased to $67.96 \% \mathrm{CrI}(020)$ and $81.15 \%(\mathrm{CrI} 110)$, respectively, after the degradation of the chitin by O. arctica YHY1. Further, peaks at $2 \theta \cong 23$ related to the polysaccharide structure of chitin showed broad scattering due to the hydrolysis of the chitin, indicating a decrease in the crystallinity [7]. Likewise, a sharp peak detected at $31.46^{\circ}$ was significantly reduced on the degradation of the chitin biomass.

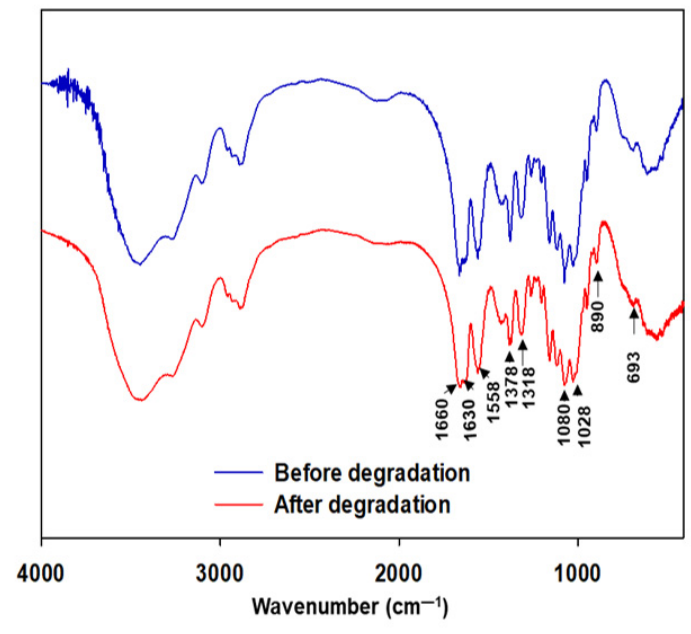

(a)

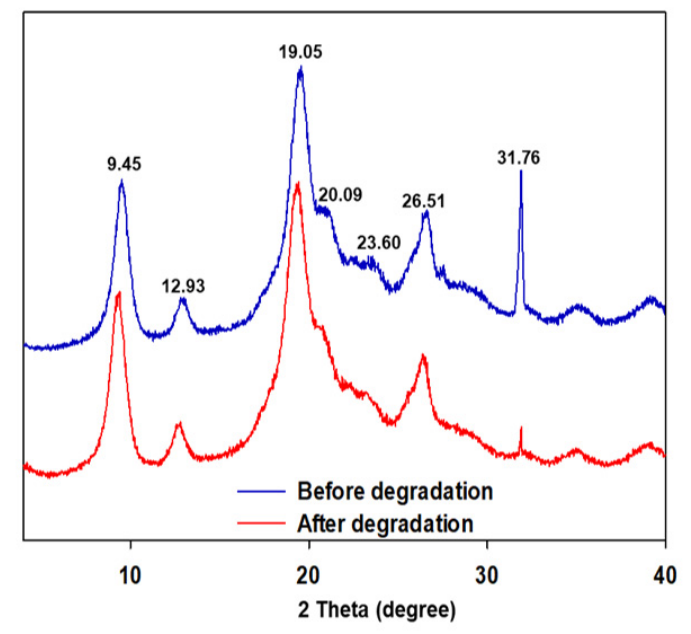

(b)

Figure 5. Structural changes in the chitin before and after degradation. (a) FTIR; (b) XRD.

\section{Conclusions}

The newly isolated halotolerant $O$. arctica YHY1 used in the present study generates a higher and stable electric current for a longer time by using seafood processing waste chitin as a carbon source. Monomeric GlcNAc and metabolites like acetate, lactate, and propionate produced during chitin degradation were consumed by strain YHY1 in a timely manner. The performance of the bacterium was improved by supplementing the MFCs with a salt concentration of $40 \mathrm{~g} \mathrm{~L}^{-1}$. Further, O. arctica YHY1 can transfer electrons directly to the anode surface using membrane-bound cytochromes, with the partly involvement of extracellular redox mediators. Therefore, the findings of the present study can provide insights for utilizing chitin waste under high salt conditions, which can serve a dual purpose of recycling the seafood chitin biomass and generating electricity.

Author Contributions: Conceptualization, R.G.; Methodology, R.G.; Software, T.-R.C.; Validation, H.-J.K. and H.-J.L.; Formal analysis, J.-Y.C.; Investigation, R.G.; Resources, S.H.; Data curation, M.-J.S.; Writing—original draft preparation, R.G.; Writing—review and editing, S.K.B., S.-K.K. and D.-W.Y.; Visualization, S.-H.K.; Supervision, Y.-H.Y.; Project administration, Y.-H.Y.; Funding acquisition, Y.-H.Y. All authors have read and agreed to the published version of the manuscript.

Funding: This study was supported by the National Research Foundation of Korea (NRF) (NRF2019R1F1A1058805 and NRF-2019M3E6A1103979) and the Research Program to Solve the Social 
Issues of the NRF funded by the Ministry of Science and ICT (2017M3A9E4077234). This work was also supported by the R\&D Program of MOTIE/KEIT (20016324).

Institutional Review Board Statement: Not applicable.

Informed Consent Statement: Not applicable.

Data Availability Statement: The data presented in this study are available on request from the corresponding author.

Conflicts of Interest: The authors declare no conflict of interest.

\section{References}

1. Nirmal, N.P.; Santivarangkna, C.; Rajput, M.S.; Benjakul, S. Trends in shrimp processing waste utilization: An industrial prospective. Trends Food Sci. Technol. 2020, 103, 20-35. [CrossRef]

2. Senphan, T.; Benjakul, S.; Kishimura, H. Characteristics and antioxidative activity of carotenoprotein from shells of Pacific white shrimp extracted using hepatopancreas proteases. Food Biosci. 2014, 5, 54-63. [CrossRef]

3. Djellouli, M.; López-Caballero, M.E.; Arancibia, M.Y.; Karam, N.; Martínez-Alvarez, O. Antioxidant and antimicrobial enhancement by reaction of protein hydrolysates derived from shrimp by-products with glucosamine. Waste Biomass Valorization 2020, 11, 2491-2505. [CrossRef]

4. Tan, Y.N.; Lee, P.P.; Chen, W.N. Microbial extraction of chitin from seafood waste using sugars derived from fruit waste-stream. AMB Express 2020, 10, 17. [CrossRef]

5. Ching, Y.C.; Redzwan, G. Biological treatment of fish processing saline wastewater for reuse as liquid fertilizer. Sustainability 2017, 9, 1062. [CrossRef]

6. Gurav, R.; Tang, J.; Jadhav, J. Novel chitinase producer Bacillus pumilus RST25 isolated from the shellfish processing industry revealed antifungal potential against phyto-pathogens. Int. Biodeterior. Biodegrad. 2017, 125, 228-234. [CrossRef]

7. Gurav, R.; Bhatia, S.K.; Choi, T.R.; Jung, H.R.; Yang, S.Y.; Song, H.S.; Park, Y.L.; Han, Y.H.; Park, J.Y.; Kim, Y.G.; et al. Chitin biomass powered microbial fuel cell for electricity production using halophilic Bacillus circulans BBL03 isolated from sea salt harvesting area. Bioelectrochemistry 2019, 130, 107329. [CrossRef]

8. Rezaei, F.; Richard, T.L.; Logan, B.E. Analysis of chitin particle size on maximum power generation, power longevity, and Coulombic efficiency in solid-substrate microbial fuel cells. J. Power Sources 2009, 192, 304-309. [CrossRef]

9. Gurav, R.; Bhatia, S.K.; Choi, T.R.; Kim, H.J.; Song, H.S.; Park, S.L.; Lee, S.M.; Lee, H.S.; Kim, S.H.; Yoon, J.J.; et al. Utilization of different lignocellulosic hydrolysates as carbon source for electricity generation using novel Shewanella marisflavi BBL25. J. Clean. Prod. 2020, 277, 124084. [CrossRef]

10. Gurav, R.; Bhatia, S.K.; Moon, Y.M.; Choi, T.R.; Jung, H.R.; Yang, S.Y.; Song, H.S.; Jeon, J.M.; Yoon, J.J.; Kim, Y.G.; et al. One-pot exploitation of chitin biomass for simultaneous production of electricity, n-acetylglucosamine and polyhydroxyalkanoates in microbial fuel cell using novel marine bacterium Arenibacter palladensis YHY2. J. Clean. Prod. 2019, 209, 324-332. [CrossRef]

11. Li, S.-W.; Zeng, R.J.; Sheng, G.-P. An excellent anaerobic respiration mode for chitin degradation by Shewanella oneidensis MR-1 in microbial fuel cells. Biochem. Eng. J. 2017, 118, 20-24. [CrossRef]

12. Li, S.W.; He, H.; Zeng, R.J.; Sheng, G.P. Chitin degradation and electricity generation by Aeromonas hydrophila in microbial fuel cells. Chemosphere 2017, 168, 293-299. [CrossRef]

13. Bhatia, S.K.; Gurav, R.; Choi, T.R.; Jung, H.R.; Yang, S.Y.; Moon, Y.M.; Song, H.S.; Jeon, J.M.; Choi, K.Y.; Yang, Y.H. Bioconversion of plant biomass hydrolysate into bioplastic (polyhydroxyalkanoates) using Ralstonia eutropha 5119. Bioresour. Technol. 2019, 271, 306-315. [CrossRef] [PubMed]

14. Focher, B.; Beltrame, P.L.; Naggi, A.; Torri, G. Alkaline N-deacetylation of chitin enhanced by flash treatments. Reaction kinetics and structure modifications. Carbohydr. Polym. 1990, 12, 405-418. [CrossRef]

15. Faria, A.; Gonçalves, L.; Peixoto, J.M.; Peixoto, L.; Brito, A.G.; Martins, G. Resources recovery in the dairy industry: Bioelectricity production using a continuous microbial fuel cell. J. Clean. Prod. 2017, 140, 971-976. [CrossRef]

16. Zhang, L.; Wang, J.; Fu, G.; Zhang, Z. Simultaneous electricity generation and nitrogen and carbon removal in single-chamber microbial fuel cell for high-salinity wastewater treatment. J. Clean. Prod. 2020, 276, 123203. [CrossRef]

17. Abbas, S.Z.; Rafatullah, M.; Ismail, N.; Shakoori, F.R. Electrochemistry and microbiology of microbial fuel cells treating marine sediments polluted with heavy metals. RSC Adv. 2018, 8, 18800-18813. [CrossRef]

18. Carmona-Martinez, A.A.; Harnisch, F.; Fitzgerald, L.A.; Biffinger, J.C.; Ringeisen, B.R.; Schröder, U. Cyclic voltammetric analysis of the electron transfer of Shewanella oneidensis MR-1 and nanofilament and cytochrome knock-out mutants. Bioelectrochemistry 2011, 81, 74-80. [CrossRef]

19. Richter, H.; Nevin, K.P.; Jia, H.; Lowy, D.A.; Lovley, D.R.; Tender, L.M. Cyclic voltammetry of biofilms of wild type and mutant Geobacter sulfurreducens on fuel cell anodes indicates possible roles of OmcB, OmcZ, type IV pili, and protons in extracellular electron transfer. Energy Environ. Sci. 2009, 2, 506-516. [CrossRef]

20. Qian, X.; Reguera, G.; Mester, T.; Lovley, D.R. Evidence that OmcB and OmpB of Geobacter sulfurreducens are outer membrane surface proteins. FEMS Microbiol. Lett. 2007, 277, 21-27. [CrossRef] 
21. Stephen, C.S. Abundance of the multiheme c-type cytochrome omcB increases in outer biofilm layers of electrode-grown Geobacter sulfurreducens. PLoS ONE 2014, 9, 104336. [CrossRef]

22. Steidl, R.J.; Lampa-Pastirk, S.; Reguera, G. Mechanistic stratification in electroactive biofilms of Geobacter sulfurreducens mediated by pilus nanowires. Nat. Commun. 2016, 7, 12217. [CrossRef] [PubMed]

23. Gurav, R.; Bhatia, S.K.; Choi, T.R.; Choi, Y.K.; Kim, H.J.; Song, H.S.; Lee, S.M.; Park, S.L.; Lee, H.S.; Koh, J.; et al. Application of macroalgal biomass derived biochar and bioelectrochemical system with Shewanella for the adsorptive removal and biodegradation of toxic azo dye. Chemosphere 2021, 264, 128539. [CrossRef] [PubMed]

24. Lee, Y.S.; Kim, K.Y. Antagonistic potential of Bacillus pumilus L1 against root-knot nematode, Meloidogyne arenaria. J. Phytopathol. 2016, 164, 29-39. [CrossRef]

25. Mao, L.; Verwoerd, W.S. Theoretical exploration of optimal metabolic flux distributions for extracellular electron transfer by Shewanella oneidensis MR-1. Biotechnol. Biofuels 2014, 7, 118. [PubMed]

26. Nakagawa, G.; Kouzuma, A.; Hirose, A.; Kasai, T.; Yoshida, G.; Watanabe, K. Metabolic characteristics of a glucose-utilizing Shewanella oneidensis strain grown under electrode-respiring conditions. PLoS ONE 2015, 10, 0138813. [CrossRef] [PubMed]

27. Zhang, A.; Wei, G.; Mo, X.; Zhou, N.; Chen, K.; Ouyang, P. Enzymatic hydrolysis of chitin pretreated by bacterial fermentation to obtain pure N-acetyl-D-glucosamine. Green Chem. 2018, 20, 2320-2327. [CrossRef]

28. Kumari, S.; Rath, P.; Kumar, A.S.; Tiwari, T.N. Extraction and characterization of chitin and chitosan from fishery waste by chemical method. Environ. Technol. Innov. 2015, 3, 77-85. [CrossRef] 